\title{
Curcumin supplementation and motor-cognitive function in healthy middle-aged and older adults
}

\author{
Jessica R. Santos-Parker ${ }^{\mathrm{a}}$, Kara L. Lubieniecki ${ }^{\mathrm{a}}$, Matthew J. Rossman ${ }^{\mathrm{a}}$, Hannah J. Van Ark ${ }^{\mathrm{a}}$, \\ Candace J. Bassett ${ }^{\mathrm{a}}$, Talia R. Strahler ${ }^{\mathrm{a}}$, Michel B. Chonchol ${ }^{\mathrm{b}}$, Jamie N. Justice ${ }^{\mathrm{a}}$ \\ and Douglas R. Seals ${ }^{\mathrm{a}, *}$ \\ ${ }^{a}$ Integrative Physiology, University of Colorado Boulder, Boulder, CO, USA \\ ${ }^{\mathrm{b}}$ Medicine (Renal Diseases and Hypertension), University of Colorado Denver, Aurora, CO, USA
}

\begin{abstract}
.
BACKGROUND: Recent studies suggest curcumin is a promising nutraceutical for improving important clinical and physiological markers of healthy aging, including motor and cognitive function.

OBJECTIVE: To determine if curcumin supplementation improves motor and cognitive function in healthy middle-aged and older adults.

METHODS: 39 healthy men and postmenopausal women (45-74 yrs) were randomized to 12 weeks of placebo $(n=19)$ or curcumin supplementation $\left(2000 \mathrm{mg} /\right.$ day Longvida $\left.{ }^{\circledR} ; n=20\right)$ with motor and cognitive function assessed at week 0 and 12 .

RESULTS: Using measures of the NIH Toolbox and other standardized tests, there were no changes in muscle strength and rate of torque development, dexterity, fatigability, mobility, endurance, and balance between the placebo and curcumin groups after 12 weeks (all $P>0.05$ ). Additionally, there were no changes after 12 weeks of placebo and curcumin supplementation in measures of fluid cognitive ability, a cognitive domain that declines with age, including processing speed, executive function, working memory, and episodic memory (all $P>0.3$ ). There were marginal changes in language, a measure of crystallized cognitive ability that is stable with age, following the intervention, wherein reading decoding increased $3 \%$ in the curcumin group (post: $2428 \pm 35$ vs. pre: $2357 \pm 34, P=0.003$ ), but was unchanged in the placebo group (post: $2334 \pm 39$ vs. pre: $2364 \pm 40, P=0.07)$.

CONCLUSIONS: Overall, 12 weeks of curcumin supplementation does not improve motor and cognitive functions in healthy middle-aged and older adults. It is possible that curcumin may enhance these functions in groups with greater baseline impairments than those studied here, including adults greater than 75 years of age and/or patients with clinical disorders.
\end{abstract}

Keywords: Aging, curcumin, motor, cognitive, NIH toolbox

\section{Introduction}

Advancing age is the primary risk factor for chronic degenerative diseases, disability, and mortality [1-3]. Antecedent and contributing to this is

\footnotetext{
*Corresponding author: Douglas R. Seals, Ph.D., Department of Integrative Physiology, University of Colorado Boulder, 354 UCB, Boulder, CO 80309, USA. Tel.: +1 303492 5305; Fax: +1 303492 6778; E-mail: seals@ colorado.edu.
}

a decline in physiological function, including motor and cognitive performance, which is not only an index of quality of life but predictive of future risk of morbidity and mortality [4-8]. With the number of older adults over the age of 65 in the U.S. expected to double by the year 2050 to $25 \%$ of the population [9], strategies to extend healthspan - the number of years of independent and healthy living - are critically needed. Interventions, including nutraceuticals, 
represent possible strategies to enhance physiological function, including motor and cognitive performance, in middle-aged and older adults.

Curcumin, the active ingredient in the Indian spice turmeric, is a promising nutraceutical for improving important clinical and physiological markers of healthy aging. Recently, our laboratory showed that 12 weeks of curcumin supplementation improves vascular endothelial function in healthy middleaged and older adults by reducing oxidative stress and increasing vascular nitric oxide bioavailability [10]. Oxidative stress, reduced nitric oxide bioavailability, and vascular endothelial dysfunction occur systemically and contribute to multiple physiological impairments and chronic diseases with aging [11-14]. Accumulating evidence suggests that these processes may be determinants of age-related motor and cognitive dysfunction [13, 15-17]. Consistent with this concept, work from our laboratory has shown that nutraceutical interventions that reduce oxidative stress, increase nitric oxide bioavailability, and improve vascular endothelial function also have potential to improve motor and cognitive function [18, 19].

Accordingly, the purpose of this study was to determine the efficacy of curcumin supplementation to improve motor and cognitive function in healthy middle-aged and older adults. To test this hypothesis, we performed a double-blind, parallel design, randomized study in which participants with baseline vascular endothelial dysfunction but free of physical or cognitive impairment received placebo or curcumin $\left(2000 \mathrm{mg} /\right.$ day, Longvida $\left.{ }^{\circledR}\right)$ supplementation for 12 weeks, as an ancillary to vascular function outcomes. We utilized the National Institutes of Health (NIH) Toolbox motor and cognitive batteries, as part of the NIH Toolbox for the Assessment of Neurological and Behavioral Function [20], in combination with other standardized motor and cognitive measures to comprehensively assess multiple subdomains of function in a time-efficient manner. Several subdomains of motor function that decline with advancing age were assessed, including muscle strength and rate of torque development [21], dexterity [22], fatigability [23], mobility [24], endurance [25], and balance [26]. Fluid cognitive ability, a domain that comprises problem solving and the ability to encode episodic memories (processing speed, executive function, working memory, and long-term memory), and which declines with aging [27, 28], also was assessed. Finally, crystalized cognitive ability, a domain that measures declarative knowledge such as vocabulary and is relatively stable with age $[27,28]$, also was evaluated.

\section{Materials and Methods}

\subsection{Participants}

Thirty-nine healthy men and postmenopausal women aged 45 to 74 years from Boulder County, Colorado and the surrounding area were studied. All participants were non-smokers, free of cognitive impairment as assessed by the Mini Mental Status Exam (MMSE > 23), and free of clinical diseases as determined by medical history, physical examination, blood chemistries, and blood pressure and electrocardiogram at rest and during an incremental treadmill exercise. All postmenopausal women were amenorrheic $\geq 1$ year and women $\leq 56$ years of age had a follicular stimulating hormone concentration $\geq 40 \mathrm{IU} / \mathrm{L}$ to confirm postmenopausal status. The trial was conducted in accordance with the Declaration of Helsinki and all procedures were reviewed and approved by the Institutional Review Board at the University of Colorado Boulder. The nature, risks, and benefits of all study procedures were explained to volunteers, and their written informed consent was obtained before participation in the study. This study was registered at ClinicalTrails.gov (NCT01968564).

\subsection{Measurements}

All measurements were performed at the University of Colorado Boulder Clinical Translational Research Center (CTRC). Participant characteristic measures, including blood assays, were performed after $a>12$-hour fast from food (water allowed), caffeine, and dietary supplements, and $>24$-hour refrainment from alcohol, physical activity, and prescription medication. Motor and cognitive measures were obtained after $a>2$-hour snack or light meal and $>24$-hour refrainment from alcohol [18].

\subsection{Curcumin administration}

In this double-blind study, participants were randomized and stratified for sex to placebo (2000 mg/day: $99.5 \%$ maltodextrin and $0.05 \%$ tartrazine, yellow food coloring) or curcumin (2000 mg/day Longvida ${ }^{\circledR}$ : 400 mg curcumin, solid 
lipid particle formulation) supplementation for 12 weeks. Capsules were provided by Verdure Sciences (Noblesville, IN) and taken each morning while fasted. Previously published work with this formulation detected circulating curcumin after $650 \mathrm{mg}$ ingestion and found that $2-4 \mathrm{~g}$ Longvida ${ }^{\circledR}$ is safe and well tolerated [29].

\subsection{Participant characteristics}

Body mass, body mass index, and waist and hip circumferences were measured by anthropometry [30]. Lean mass and percent body fat were determined with dual-energy X-ray absorptiometry (DEXA; GE Lunar Prodigy Advance). Resting brachial artery systolic and diastolic blood pressures and heart rate were measured in triplicate with a semi-automated device (Dinamap XL, Johnson \& Johnson). Maximal aerobic capacity $\left(\mathrm{VO}_{2} \max \right)$ was determined from open circuit spirometry during an incremental treadmill exercise test (Balke protocol) to exhaustion [31]. Weekly physical activity energy expenditure was assessed with the Community Healthy Activities Model Program for Seniors questionnaire [32]. All blood samples were collected from the cubital vein and assayed by the Colorado Clinical and Translational Sciences Institute CTRC Core laboratory or the Boulder Community Hospital Clinical laboratory, as previously described [19]. Briefly, fasting glucose, insulin, and serum lipids were determined by reflective spectrophotometry (Ortho Clinical Diagnostics), radioimmunoassay (Millipore), or standard assays, respectively.

\subsection{Motor measurements}

Motor function was assessed with select measures of the NIH Toolbox Motor Battery as previously described [33], including domains of strength (Grip Strength Test), dexterity (9-Hole Pegboard Dexterity Test), and mobility (4-Meter Walk Gait Speed Test). In addition to the NIH Toolbox, strength (knee flexion and extension torque; Chair Stand Test) and rate of torque development (knee flexion and extension), mobility (stair ascent test), endurance (6-Minute Walk Test; treadmill endurance during a Balke treadmill task), balance (rapid step test time and number of errors), and fatigability (heel-rise test; Fatigue Severity Scale questionnaire) were also evaluated with other established measures as described previously by our laboratory and others [18, 31, 34-39].

\subsection{Cognition measurements}

Cognitive function was evaluated with the NIH Toolbox-Cognition Battery (desktop version) as previously described [28, 40]. Briefly, the NIH Toolbox-Cognition Battery entails seven computerized tests that assess five major cognitive subdomains including processing speed (Pattern Comparison Processing Speed Test), executive function (Dimensional Change Card Sort Test; Flanker Inhibitory Control and Attention Test), working memory (List Sorting Working Memory Test), episodic memory (Picture Sequence Memory Test), and language (Picture Vocabulary Test; Oral Reading Recognition Test). The fluid composite cognition score is a combination of the NIH Toolbox tests assessing the subdomains of fluid cognitive ability: processing speed, executive function, working memory, and episodic memory. The crystallized cognition composite score is a combination of the tests assessing the subdomain of crystallized cognitive ability: language. The total cognitive function composite score, a measure of general cognitive function, is a combination of all tests listed under the fluid and crystallized composites. In addition to the NIH Toolbox-Cognition Battery, the Trail Making Test (TMT) parts A and B were administered to determine processing speed and executive function, respectively [41]. Fluid cognitive ability is primarily dependent on biological processes and declines with advancing age. In contrast, crystallized ability is influenced largely by knowledge acquired through the lifetime, is stable with age, and is not expected to change with curcumin but was included as part of the NIH Toolbox [27, 28].

\subsection{Data analysis}

Data are expressed as mean \pm standard error (SE). Statistical analysis was performed with IBM SPSS 23. Data normality was assessed with the ShapiroWilk test and non-normally distributed variables were $\log$ base ten transformed for parametric statistical analysis. Outliers ( $\geq 3$ standard deviations) were removed for pairwise analysis. An independent $t$-test was performed to assess group differences at baseline. A mixed-model ANOVA was performed to identify group (placebo vs. curcumin) by time (week 0 vs. 12) interactions for all primary outcomes and clinical characteristics. Additionally, for all primary outcomes, age was added as a covariate to each 
Table 1

Participant characteristics

\begin{tabular}{|c|c|c|c|c|}
\hline & \multicolumn{2}{|c|}{ Placebo } & \multicolumn{2}{|c|}{ Curcumin } \\
\hline & Week 0 & Week 12 & Week 0 & Week 12 \\
\hline $\mathrm{N}$, men/women & $11 / 8$ & - & $10 / 10$ & - \\
\hline Age, years & $61 \pm 2$ & - & $63 \pm 2$ & - \\
\hline Body mass, $\mathrm{kg}$ & $76 \pm 3^{*}$ & $75 \pm 3$ & $68 \pm 2$ & $68 \pm 3$ \\
\hline Body mass index, $\mathrm{kg} / \mathrm{m}^{2}$ & $25 \pm 1$ & $25 \pm 1$ & $24 \pm 1$ & $24 \pm 1$ \\
\hline Waist to hip ratio, $\mathrm{U}^{\mathrm{L}}$ & $0.81 \pm 0.05$ & $0.85 \pm 0.02$ & $0.84 \pm 0.02$ & $0.84 \pm 0.02$ \\
\hline Lean mass, $\mathrm{kg}$ & $53 \pm 2$ & $52 \pm 2$ & $47 \pm 2$ & $47 \pm 2$ \\
\hline Body fat, $\%$ & $27.9 \pm 2.0$ & $27.8 \pm 2.0$ & $30.1 \pm 1.9$ & $30.2 \pm 1.9$ \\
\hline Systolic blood pressure, $\mathrm{mmHg}$ & $120 \pm 3$ & $122 \pm 3$ & $121 \pm 3$ & $121 \pm 3$ \\
\hline Diastolic blood pressure, $\mathrm{mmHg}$ & $73 \pm 2$ & $73 \pm 1$ & $72 \pm 1$ & $71 \pm 1$ \\
\hline Resting heart rate, beats $/ \mathrm{min}^{\mathrm{L}}$ & $56 \pm 2$ & $55 \pm 2$ & $55 \pm 1$ & $57 \pm 2$ \\
\hline Fasting glucose, $\mathrm{mg} / \mathrm{dL}$ & $84 \pm 2$ & $85 \pm 2$ & $85 \pm 2$ & $87 \pm 2$ \\
\hline Fasting insulin, $\mu \mathrm{U} / \mathrm{mL}^{\mathrm{L}}$ & $8 \pm 1$ & $8 \pm 1$ & $7 \pm 1$ & $8 \pm 1$ \\
\hline Total cholesterol, mg/dL & $177 \pm 6$ & $173 \pm 6$ & $175 \pm 8$ & $174 \pm 6$ \\
\hline High density lipoprotein-cholesterol, mg/dL $\mathrm{d}^{\mathrm{L}}$ & $56 \pm 4$ & $52 \pm 4$ & $55 \pm 5$ & $56 \pm 4$ \\
\hline Low density lipoprotein-cholesterol, mg/dL & $103 \pm 6$ & $102 \pm 6$ & $103 \pm 7$ & $101 \pm 6$ \\
\hline Triglycerides, $\mathrm{mg} / \mathrm{dL}^{\mathrm{L}}$ & $97 \pm 15$ & $93 \pm 15$ & $86 \pm 11$ & $91 \pm 12$ \\
\hline $\mathrm{VO}_{2} \max , \mathrm{mL} / \mathrm{kg} / \mathrm{min}$ & $33 \pm 1$ & $33 \pm 1$ & $31 \pm 1$ & $31 \pm 1$ \\
\hline Physical activity energy expenditure, $\mathrm{kcal} / \mathrm{wk}^{\mathrm{L}}$ & $6095 \pm 872$ & $5334 \pm 819$ & $5720 \pm 954$ & $5416 \pm 984$ \\
\hline
\end{tabular}

Data are mean $\pm \mathrm{SE} ;{ }^{\mathrm{L}}$ Data $\log$ transformed for statistical analysis; ${ }^{*} P=0.03$ vs. curcumin week 0 .

ANOVA to determine if age modified the response to the intervention. In the case of significant interactions, a paired $t$-test was performed for within group comparisons with Bonferroni correction. Statistical significance was set at $\alpha<0.05$.

\section{Results}

\subsection{Participants}

Participant characteristics, exclusion, withdrawal, adherence, safety, and vascular outcomes for this study have been previously reported [10]. Overall, thirty-nine subjects were included in analysis (placebo $n=19$, curcumin $n=21$ ). Individuals were of non-Hispanic Caucasian $(n=32)$, non-Hispanic Asian $(n=3)$, Hispanic Caucasian $(n=2)$, nonHispanic African American $(n=1)$, or non-Hispanic American Indian/Alaskan $(n=1)$ ethnicity and race, respectively. All participants had some level of college education, with $\sim 80 \%$ having a Bachelor's or graduate degree.

\subsection{Participant characteristics}

All participant characteristics (age, body mass index, waist to hip ratio, lean mass, percent body fat, blood pressures, glucose, insulin, lipids, aerobic capacity, and physical activity energy expenditure) were not different between groups at baseline (all $P>0.05)$, except for body mass, which was higher in the placebo group $(P=0.03)$. No participant characteristics changed with time (all $P>0.2$ ) or with time between groups (all $P>0.1$; Table 1).

\subsection{Motor measurements}

All motor function outcomes are presented in Table 2. Motor function measures were not different at baseline between the placebo and curcumin groups (all $P>0.1$ ). Additionally, there were no time $(P>0.1)$ or group by time interactions $(P>0.05)$ for measures of muscle strength (grip strength, chair stand, knee flexion and extension torque) and rate of torque development, dexterity (9-hole pegboard dexterity), mobility (4-meter walk gait speed, stair ascent), endurance (treadmill endurance), balance (rapid step test time), and fatigability (heel rise). 6-minute walk distance increased $2 \%(P=0.02)$, the number of errors for the rapid step test was lower $(P=0.004)$, and scores on the Fatigue Severity Scale questionnaire were lower with time $(P=0.02)$, however there were no group by time interactions for these measures (all $P>0.4$ ). The addition of age as a covariate for all motor measurements did not alter the above reported responses to the intervention. 
Table 2

Measures of motor function before and after 12 weeks of placebo or curcumin supplementation

\begin{tabular}{|c|c|c|c|c|c|c|}
\hline & \multicolumn{2}{|c|}{ Placebo } & \multicolumn{2}{|c|}{ Curcumin } & \multicolumn{2}{|c|}{$P$ value } \\
\hline & Week 0 & Week 12 & Week 0 & Week 12 & Time & $\begin{array}{c}\text { Group by } \\
\text { time }\end{array}$ \\
\hline \multicolumn{7}{|l|}{ Muscle strength } \\
\hline${ }^{\text {NIHTB }}$ Grip strength, $\mathrm{kg}^{\mathrm{L}}$ & $32.6 \pm 1.8$ & $33.5 \pm 2.0$ & $29.9 \pm 2.4$ & $30.1 \pm 2.4$ & 0.5 & 0.6 \\
\hline Chair stand, s & $9.4 \pm 0.5$ & $8.8 \pm 0.6$ & $8.5 \pm 0.3$ & $8.8 \pm 0.3$ & 0.4 & 0.05 \\
\hline Knee flexion torque, $\mathrm{J}$ & $78.4 \pm 7.6$ & $73.3 \pm 7.3$ & $69.1 \pm 4.8$ & $64.3 \pm 7.0$ & 0.3 & 0.97 \\
\hline Knee extension torque, $\mathrm{J}^{\mathrm{L}}$ & $83.6 \pm 14.7$ & $62.4 \pm 8.5$ & $74.8 \pm 9.9$ & $65.9 \pm 7.7$ & 0.1 & 0.7 \\
\hline \multicolumn{7}{|l|}{ Muscle rate of torque development (RTD) } \\
\hline Knee flexion RTD, J/s & $737.5 \pm 130.0$ & $626.2 \pm 94.2$ & $557.0 \pm 96.7$ & $498.7 \pm 52.1$ & 0.1 & 0.6 \\
\hline Knee extension RTD, J/s ${ }^{\mathrm{L}}$ & $554.8 \pm 93.2$ & $481.3 \pm 60.4$ & $582.2 \pm 88.5$ & $548.9 \pm 77.7$ & 0.5 & 0.4 \\
\hline \multicolumn{7}{|l|}{ Manual dexterity } \\
\hline NIHTB 9-hole pegboard dexterity, s & $20 \pm 1$ & $20 \pm 1$ & $20 \pm 1$ & $19 \pm 1$ & 0.2 & 0.6 \\
\hline \multicolumn{7}{|l|}{ Mobility } \\
\hline $\mathrm{NIHTB}_{4}$-meter walk gait speed, m/s & $1.2 \pm 0.04$ & $1.2 \pm 0.04$ & $1.2 \pm 0.04$ & $1.2 \pm 0.03$ & 0.98 & 0.9 \\
\hline Stair ascent, $\mathrm{s}^{\mathrm{L}}$ & $3.5 \pm 0.2$ & $3.5 \pm 0.2$ & $3.5 \pm 0.1$ & $3.6 \pm 0.1$ & 0.4 & 0.6 \\
\hline \multicolumn{7}{|l|}{ Endurance } \\
\hline 6-minute walk, m & $606.7 \pm 17.9$ & $616.2 \pm 19.3$ & $585.2 \pm 14.6$ & $600.2 \pm 11.6$ & 0.02 & 0.6 \\
\hline Treadmill endurance, $\mathrm{s}$ & $582 \pm 18$ & $587 \pm 26$ & $543 \pm 19$ & $544 \pm 26$ & 0.7 & 0.8 \\
\hline \multicolumn{7}{|l|}{ Balance } \\
\hline Rapid step test, $\mathrm{s}^{\mathrm{L}}$ & $33.7 \pm 1.0$ & $32.8 \pm 1.0$ & $35.1 \pm 1.0$ & $33.9 \pm 1.0$ & 0.2 & 0.9 \\
\hline Rapid step test error & $2.3 \pm 0.4$ & $1.8 \pm 0.4$ & $2.4 \pm 0.3$ & $1.4 \pm 0.2$ & 0.004 & 0.4 \\
\hline \multicolumn{7}{|l|}{ Fatigability } \\
\hline Heel-rise, s & $115 \pm 11$ & $91 \pm 9$ & $112 \pm 20$ & $129 \pm 36$ & 0.8 & 0.3 \\
\hline Fatigue severity scale ${ }^{\mathrm{L}}$ & $18 \pm 2$ & $16 \pm 2$ & $19 \pm 2$ & $16 \pm 2$ & 0.02 & 0.9 \\
\hline
\end{tabular}

Data are mean $\pm \mathrm{SE}$; ${ }^{\mathrm{NIHTB}} \mathrm{NIH}$ Toolbox measure; ${ }^{\mathrm{L}}$ Data log transformed for statistical analysis.

\subsection{Cognitive measurements}

All cognitive function outcomes are presented in Table 3. There were no baseline differences in individual tests of cognitive function between the placebo and curcumin group (all $P>0.1)$. There were no changes with time (all $P>0.05$ ) or group by time interactions (all $P>0.06$ ) for processing speed (pattern comparison processing speed, trail making test-A), executive function (dimensional change card sort, trail making test-B), working memory (list sorting working memory), and language (picture vocabulary) between the placebo and curcumin group. However, flanker inhibitory control and attention, a measure of executive function increased $2 \%$ $(P=0.04)$ and picture sequence memory, a measure of episodic memory increased $7 \%(P<0.05)$ with time but there was no group by time interactions (both $P>0.3)$. Additionally, there was no change with time $(P=0.2)$ for reading decoding, but a group by time interaction $(P=0.001)$ was observed. Reading decoding was unchanged in the placebo group $(P=0.07)$ but there was a $3 \%$ increase in the curcumin group $(P=0.003)$ after 12 weeks.

There were no baseline differences in fluid, crystallized, and total cognitive function composite scores between groups (all $P>0.4$ ). At baseline the placebo group's age-adjusted national percentile for the fluid, crystallized, and total cognitive function composite scores were at the 68th, 87th, and 83rd percentile, respectively, where the curcumin group scored at the 65th, 92nd, and 87th percentile, respectively, with no differences between groups (all $P>0.5$ ). Fluid and crystallized composite cognition scores slightly increased $1-2 \%$ with time (both $P=0.07$ ) but there was no change with time between groups (both $P>0.3$ ). Total cognitive function composite score, a combination of all tests under fluid and crystallized composites, marginally increased by $2 \%$ with time $(P=0.03)$ but no group by time interaction $(P=0.3)$ between the placebo and curcumin group was observed. The addition of age as a covariate for all cognitive measurements did not alter the above reported response to the intervention.

\section{Discussion}

This is the first study to assess the effects of curcumin supplementation on motor and cognitive function in healthy middle-aged and older individuals. After 12 weeks of curcumin supplementation 
Table 3

Measures of cognitive function before and after 12 weeks of placebo or curcumin supplementation

\begin{tabular}{|c|c|c|c|c|c|c|}
\hline & \multicolumn{2}{|c|}{ Placebo } & \multicolumn{2}{|c|}{ Curcumin } & \multicolumn{2}{|c|}{$P$ value } \\
\hline & Week 0 & Week 12 & Week 0 & Week 12 & Time & $\begin{array}{l}\text { Group by } \\
\text { time }\end{array}$ \\
\hline \multicolumn{7}{|l|}{ Processing speed } \\
\hline NIHTB Pattern comparison processing speed & $51 \pm 2$ & $52 \pm 2$ & $55 \pm 3$ & $58 \pm 3$ & 0.2 & 0.5 \\
\hline Trail making test-A, $\mathrm{s}^{\mathrm{L}}$ & $27.02 \pm 1.91$ & $25.68 \pm 1.77$ & $28.02 \pm 2.05$ & $27.67 \pm 1.94$ & 0.4 & 0.6 \\
\hline \multicolumn{7}{|l|}{ Executive function } \\
\hline${ }^{\text {NIHTB }}$ Dimensional change card sort & $8.13 \pm 0.12$ & $8.13 \pm 0.16$ & $7.78 \pm 0.14$ & $7.93 \pm 0.17$ & 0.4 & 0.4 \\
\hline${ }^{\text {NIHTB }}$ Flanker inhibitory control and attention & $8.3 \pm 0.1$ & $8.5 \pm 0.1$ & $8.3 \pm 0.1$ & $8.5 \pm 0.1$ & 0.04 & 0.97 \\
\hline Trail making test- $\mathrm{B}, \mathrm{s}^{\mathrm{L}}$ & $61.70 \pm 4.13$ & $58.08 \pm 4.71$ & $57.20 \pm 5.31$ & $52.88 \pm 3.83$ & 0.1 & 0.9 \\
\hline \multicolumn{7}{|l|}{ Working memory } \\
\hline NIHTB List sorting working memory & $17 \pm 1$ & $17 \pm 1$ & $17 \pm 1$ & $17 \pm 1$ & 0.5 & 0.97 \\
\hline \multicolumn{7}{|l|}{ Episodic memory } \\
\hline${ }^{\text {NIHTB }}$ Picture sequence memory & $487.4 \pm 23.6$ & $501.7 \pm 25.3$ & $475.1 \pm 22.2$ & $516.8 \pm 25.6$ & 0.05 & 0.3 \\
\hline \multicolumn{7}{|l|}{ Language } \\
\hline NIHTB Picture vocabulary & $1890.2 \pm 36.8$ & $1952.0 \pm 46.9$ & $1970.2 \pm 40.3$ & $1968.3 \pm 45.5$ & 0.08 & 0.06 \\
\hline NIHTB Oral reading recognition & $2364 \pm 40$ & $2334 \pm 39$ & $2357 \pm 34$ & $2428 \pm 35^{*}$ & 0.2 & 0.001 \\
\hline \multicolumn{7}{|l|}{ Cognitive function composite scores } \\
\hline NIHTB Fluid & $101.6 \pm 1.8$ & $103.1 \pm 2.2$ & $101.5 \pm 2.3$ & $104.2 \pm 2.8$ & 0.07 & 0.6 \\
\hline${ }^{\text {NIHTB }}$ Crystallized & $129.5 \pm 2.4$ & $130.2 \pm 2.5$ & $131.7 \pm 2.4$ & $133.7 \pm 2.6$ & 0.07 & 0.3 \\
\hline${ }^{\text {NIHTB }}$ Total & $119.7 \pm 2.6$ & $121.3 \pm 3.4$ & $122.9 \pm 3.4$ & $126.8 \pm 4.1$ & 0.03 & 0.3 \\
\hline
\end{tabular}

Data are mean $\pm \mathrm{SE} ;{ }^{\mathrm{NIHTB}}$ NIH Toolbox measure; ${ }^{\mathrm{L}}$ Data $\log$ transformed for statistical analysis; $* P=0.003$ vs. curcumin week 0 .

compared with placebo, there were no changes in any subdomains of motor or cognitive function as assessed with the NIH Toolbox and other standardized tests, except for a marginal 3\% increase in reading decoding ability. Overall, the present findings suggest that 12 weeks of curcumin supplementation has no apparent effect on motor or cognitive function domains that decline with age in healthy high-functioning middle-aged and older adults.

\subsection{Curcumin supplementation and motor function}

Motor function, including muscle strength, dexterity, fatigability, mobility, endurance, and balance, decline with advancing age [21-26] and are predictive of current and future disability and mortality [4-6, 37, 42]. Identification of intervention strategies that delay the onset of age-related declines in physiological function, including motor ability, hold promise to improve independence and quality of life.

Information on the effects of curcumin supplementation on motor function in the context of aging is surprisingly limited. In animal models of chronic disease, including Parkinson's disease, curcumin protects against disease-associated motor impairments [43, 44], whereas no studies in preclinical models of healthy aging have been performed. In humans, one investigation reported a decline in self-reported physical fatigue after 4-weeks of curcumin supplementation in healthy older adults [45], however no other studies have assessed the impact of curcumin supplementation on multiple subdomains of motor performance in middle-aged and older adults without evident motor impairment. In the present trial, we found no evidence of improvement in any subdomain of motor function after 12 weeks of curcumin supplementation. A minor time effect was observed for some motor function measures (rapid step error, fatigue severity scale, and six-minute walk) after the 12-week intervention. It is difficult to discern if this was a slight practice effect or due to a type 1 error. Regardless, there was no evidence in our study that 12 weeks of curcumin supplementation influenced motor function in healthy middle-aged and older adults.

\subsection{Curcumin supplementation and cognitive function}

Advancing age is associated with a decline in cognitive function, which primarily manifests as reduced fluid ability-the ability to solve novel problems and encode episodic memories $(27,28]$. Maintaining optimal levels of cognitive function during aging would contribute importantly to preservation of healthspan.

In animal models of chronic disease, primarily Alzheimer's disease, curcumin attenuates 
disease-associated cognitive impairments [46-49]. Furthermore, curcumin improves cognitive function, including learning and memory, in rodent models of accelerated aging $[50,51]$ as well as healthy older rodents [52-54]. Findings regarding the effect of curcumin on cognitive function in older humans have been inconsistent. Cox et al. reported that in participants who were on average older than those in the current study (60-85 vs. 45-74 yrs), 4 weeks of curcumin supplementation improved working memory and attention [45]. Another investigation in middleaged and older adults, including individuals with and without risk factors for cardiovascular disease (e.g., hypertension), found that 12 months of curcumin supplementation had no effect on multiple subdomains of cognitive function [55]. In contrast to previous investigations, the current trial was conducted in entirely healthy individuals and included both middle-aged and older adults. In these participants, 12 weeks of curcumin supplementation did not influence any subdomains of cognitive function that decline with age. Although there was a minor 3\% increase in reading decoding ability, these data are difficult to interpret because this measure of crystallized ability remains stable with aging and, as such, was not expected to change with intervention.

Although in the present study we used the same curcumin formulation as the study by Cox et al. [45], even a higher dose (2000 vs. $400 \mathrm{mg} /$ day Longvida ${ }^{\circledR}$ ), differences between our investigation and that by Cox et al. may be due to a number of different factors, including the tests used to measure working memory or participant age. The subjects in the study by Cox et al. were all over the age of 60 (60-85 yrs) whereas individuals in the current trial were on average younger (45-74 yrs). Additionally, Cox et al. cited age-related differences in cognitive function between their subjects and young individuals, but baseline age percentiles for fluid and relative cognitive ability of the participants were not reported. As such, it is possible that subjects in the current study had higher baseline cognitive function and less potential for improvement with curcumin supplementation ("ceiling effect"), as discussed next.

\subsection{Relation with vascular endothelial function and potential influence of baseline function}

We have previously reported that 12 weeks of curcumin supplementation improved vascular endothelial function by $35-40 \%$ in the participants of the present investigation. Vascular endothelial function has been suggested to be a determinant of motor and cognitive function in older adults $[15,16,56]$, and there are examples of other nutraceuticals improving vascular, motor, and cognitive function in healthy middle-aged and older adults $[18,19]$. In contrast, despite improving vascular endothelial function by reducing oxidative stress and increasing vascular nitric oxide bioavailability [10], we found no significant group changes in motor or cognitive function with curcumin supplementation in the present analysis. To further explore potential links between changes in vascular endothelial function and cognitive and/or motor function with curcumin supplementation in our cohort, we assessed the relation between improvements in cognitive and motor function (present analysis) and brachial artery flow-mediated dilation from our previously published data [10]. We found no significant correlations between individual changes in vascular endothelial function and cognitive or motor functions in response to 12 weeks of curcumin supplementation. Thus, although vascular function, oxidative stress, and nitric oxide bioavailability influence systemic processes, improvements in these biological properties did not translate to changes in motor or cognitive functions in the present group of healthy middle-aged and older adults. It is possible that these functions are not strongly related in healthy adults, or that the magnitude and/or duration (12-week intervention) of the improvements were not sufficient to evoke corresponding improvements in motor or cognitive performance this group.

Concerning the first possible explanation, subjects in this curcumin supplementation study were recruited based on the presence of impaired baseline vascular endothelial function, as this was a primary outcome. In contrast, participants were within the normal expected age ranges for motor and function, including gait speed [57], endurance [58], and strength [59]. Our subjects were not only free from baseline cognitive dysfunction (e.g., mild cognitive impairments or dementia), but had some form of higher education, and were well above the national age percentile for cognitive function at baseline (the curcumin group scored at the 65th and 92nd percentile for fluid and crystallized composite scores, respectively). Thus, any potential improvements in cognitive function would likely be difficult to detect given the high initial cognitive abilities of our participants. Although curcumin had no effect on motor or cognitive function in this healthy population, future 
studies are needed to determine if curcumin may improve motor or cognitive function in individuals with lower baseline motor and cognitive function or clinical impairments in these functional domains.

\subsection{Short-term intervention and NIH Toolbox cognitive battery}

The NIH Toolbox motor and cognitive batteries are recently released standardized batteries that are part of the NIH Toolbox for the Assessment of Neurological and Behavioral Function specifically developed for use in intervention studies and clinical trials. These validated, time-efficient batteries allow for the comprehensive assessment of multiple domains of motor and cognitive function, enabling standardized measurements and age comparisons across studies. Due to its recent availability, all previous reports in healthy adults have been cross-sectional comparisons [33, 60-62] or re-testing performed after 2 weeks for validation [40, 63-66]. To our knowledge, this is the first investigation to utilize the NIH Toolbox motor and cognitive batteries in an intervention study. It is important to acknowledge that many of the measures of the NIH Toolbox cognitive battery demonstrated a time effect during re-testing, 12 weeks after baseline. Previous studies when re-testing has been performed after 2 weeks have provided evidence of practice effects for the cognitive battery [62-64]. We are unable to discern if the slight improvements in the cognitive scores with time observed in the current trial are due to true learning effects or a result of a drift in testing scores, as improvements were minor, ranging from 1 to $7 \%$. Regardless, our placebo-controlled experimental design allowed us to evaluate the potential independent effects of curcumin, and we did not document any additive influence of curcumin in cognitive tests where learning effects were observed. However, more studies are needed to determine if longer intervention times are needed to avoid the observed time effects when using the NIH Toolbox cognitive battery.

\subsection{Limitations}

This study was primarily in Caucasian men and women; therefore, it is unknown if curcumin supplementation improves motor or cognitive function in healthy middle-aged and older adults of other ethnicities. Additionally, as discussed above, the participants in the present trial were mainly college educated and had high cognitive function, and were also free from motor impairments. Individuals with chronic diseases or clinically significant impairments were not included in this investigation to initially evaluate the effects of curcumin on healthy aging.

\subsection{Conclusions}

In healthy, well-educated middle-aged and older adults without motor or cognitive impairments and high age-adjusted baseline performance, 12 weeks of curcumin supplementation did not influence motor or cognitive function domains that decline with age. These data support the view that adding curcumin supplements to the normal diet will likely not further enhance motor or cognitive performance in that subgroup of the aging population. However, additional studies are needed to determine if curcumin supplementation has beneficial effects in individuals or groups with more significantly reduced baseline motor and cognitive function as a result of older age and/or clinical disorders.

\section{Acknowledgments}

The authors thank Jonathan J. Herrera, Chasen W. Daugherty, and the staff of the University of Colorado Boulder Clinical and Translational Research Center for their technical assistance. J.N.J. is currently at Internal Medicine - Section on Gerontology and Geriatrics at Wake Forest School of Medicine, Winston-Salem, NC (current affiliated email: jnjustic@wakehealth.edu). This work was supported by National Institutes of Health awards R21 AG042795, Colorado CTSA UL1 TR001082, T32 AG000279-14S1, R37 AG013038-17S1, and R21 AG042795-01A1S1. Contents are the authors' sole responsibility and do not necessarily represent official National Institutes of Health views. The authors have no declarations to disclose.

\section{References}

[1] Seals DR, Justice JN, LaRocca TJ. Physiological geroscience: Targeting function to increase healthspan and achieve optimal longevity. J Physiol. 2016;594(8):2001-24.

[2] Franceschi C, Campisi J. Chronic inflammation (inflammaging) and its potential contribution to age-associated diseases. J Gerontol A Biol Sci Med Sci. 2014;69(Suppl 1):S4-9.

[3] Kennedy BK, Berger SL, Brunet A, Campisi J, Cuervo AM, Epel ES, Franceschi C, Lithgow GJ, Morimoto RI, Pessin 
JE, Randon TA, Richardson A, Schadt EE, Wyss-Coray T, Sierra F. Geroscience: Linking aging to chronic disease. Cell. 2014;159(4):709-13.

[4] Sasaki H, Kasagi F, Yamada M, Fujita S. Grip strength predicts cause-specific mortality in middle-aged and elderly persons. Am J Med. 2007;120(4):337-42.

[5] Studenski S, Perera S, Patel K, Rosano C, Faulkner K, Inzitari M, Brach J, Chandler J, Cawthon P, Connor EB, Nevitt M, Visser M, Kritchevsky S, Badinelli S, Harris T, Newman AB, Cauley J, Ferrucci L, Guralnik J. Gait speed and survival in older adults. JAMA. 2011;305(1):50-8.

[6] Newman AB, Simonsick EM, Naydeck BL, Boudreau RM, Kritchevsky SB, Nevitt MC, Pahor M, Satterfield S, Brach JS, Studenski SA, Harris TB. Association of long-distance corridor walk performance with mortality, cardiovascular disease, mobility limitation, and disability. JAMA. 2006;295(17):2018-26.

[7] Vazzana R, Bandinelli S, Lauretani F, Volpato S, Lauretani F, Di Iorio A, Abate M, Corsi AM, Milaneschi Y, Guralnik JM, Ferrucci L. Trail Making Test predicts physical impairment and mortality in older persons. J Am Geriatr Soc. 2010;58(4):719-23.

[8] Blacker D, Lee H, Muzikansky A, Martin EC, Tanzi R, McArdle JJ, Moss M, Albert M. Neuropsychological measures in normal individuals that predict subsequent cognitive decline. Arch Neurol. 2007;64(6):862-71.

[9] Population Projections. Table 12. Projections of the populations by age and sex for the United States 2010 to 2050 [Internet]. 2008. Available from: http://www.cen sus.gov/population/projections/data/national/2008/summary tables.html.

[10] Santos-Parker JR, Strahler TR, Bassett CJ, Bispham NZ, Chonchol MB, Seals DR. Curcumin supplementation improves vascular endothelial function in healthy middle-aged and older adults by increasing nitric oxide bioavailability and reducing oxidative stress. Aging (Albany NY). 2017;9(1):187-208.

[11] Feletou M, Vanhoutte PM. Endothelial dysfunction: A multifaceted disorder (The Wiggers Award Lecture). Am J Physiol Heart Circ Physiol. 2006;291(3):H985-1002.

[12] Le Brocq M, Leslie SJ, Milliken P, Megson IL. Endothelial dysfunction: From molecular mechanisms to measurement, clinical implications, and therapeutic opportunities. Antioxid Redox Signal. 2008;10(9):1631-74.

[13] Paul V, Ekambaram P. Involvement of nitric oxide in learning \& memory processes. Indian J Med Res. 2011;133:471-8.

[14] Thompson CS, Hakim AM. Living beyond our physiological means: Small vessel disease of the brain is an expression of a systemic failure in arteriolar function: A unifying hypothesis. Stroke. 2009;40(5):e322-30.

[15] Heffernan KS, Chale A, Hau C, Cloutier GJ, Phillips EM, Warner P, Nickerson H, Reid KF, Kuvin JT, Fielding RA. Systemic vascular function is associated with muscular power in older adults. J Aging Res. 2012;2012:386387.

[16] Welsch MA, Dobrosielski DA, Arce-Esquivel AA, Wood RH, Ravussin E, Rowley C, Jazwinski SM. The association between flow-mediated dilation and physical function in older men. Med Sci Sports Exerc. 2008;40(7): 1237-43.

[17] Grassi D, Ferri L, Cheli P, Di Giosia P, Ferri C. Cognitive decline as a consequence of essential hypertension. Curr Pharm Des. 2011;17(28):3032-8.
[18] Justice JN, Johnson LC, DeVan AE, Cruickshank-Quinn C, Reisdorph N, Bassett CJ, Evans TD, Brooks FA, Bryan NS, Chonchol MB, Giordano T, McQueen MB, Seals DR. Improved motor and cognitive performance with sodium nitrite supplementation is related to small metabolite signatures: A pilot trial in middle-aged and older adults. Aging (Albany NY). 2015;7(11):1004-21.

[19] DeVan AE, Johnson LC, Brooks FA, Evans TD, Justice JN, Cruickshank-Quinn C, Reisdorph N, Bryan NS, McQueen MB, Santos-Parker JR, Chonchol MB, Bassett CJ, Sindler Al, Giordano T, Seals DR. Effects of sodium nitrite supplementation on vascular function and related small metabolite signatures in middle-aged and older adults. J Appl Physiol (1985). 2016;120(4):416-25.

[20] Gershon RC, Wagster MV, Hendrie HC, Fox NA, Cook KF, Nowinski CJ. NIH toolbox for assessment of neurological and behavioral function. Neurology. 2013;80(11 Suppl 3):S2-6.

[21] Thompson BJ, Ryan ED, Sobolewski EJ, Conchola EC, Cramer JT. Age related differences in maximal and rapid torque characteristics of the leg extensors and flexors in young, middle-aged and old men. Exp Gerontol. 2013;48(2):277-82.

[22] Mathiowetz V, Volland G, Kashman N, Weber K. Adult norms for the Box and Block Test of manual dexterity. Am J Occup Ther. 1985;39(6):386-91.

[23] Jan MH, Chai HM, Lin YF, Lin JC, Tsai LY, Ou YC, Lin DH. Effects of age and sex on the results of an ankle plantar-flexor manual muscle test. Phys Ther. 2005;85(10): 1078-84.

[24] Bohannon RW. Comfortable and maximum walking speed of adults aged 20-79 years: Reference values and determinants. Age Ageing. 1997;26(1):15-9.

[25] Enright PL, Sherrill DL. Reference equations for the sixminute walk in healthy adults. Am J Respir Crit Care Med. 1998;158(5 Pt 1):1384-7.

[26] Medell JL, Alexander NB. A clinical measure of maximal and rapid stepping in older women. J Gerontol A Biol Sci Med Sci. 2000;55(8):M429-33.

[27] Kensinger EA, Corkin S. Cognition in aging and age related disease. Handbook of the Neuroscience of Aging. 2009:24956.

[28] Jerry Slotkin CN, Ron Hays, Jennifer Beaumont, James Griffith, Susan Magasi, John Salsman, Richard Gershon. NIH Toolbox scoring and interpretation guide. 2012.

[29] Gota VS, Maru GB, Soni TG, Gandhi TR, Kochar N and Agarwal MG. Safety and pharmacokinetics of a solid lipid curcumin particle formulation in osteosarcoma patients and healthy volunteers. J Agric Food Chem. 2010;58(4):20952099.

[30] Lohman TG, Roche AF, Martorell R. Anthropometric standardization reference manual. Human Kinetics. 1988.

[31] Evans SL, Davy KP, Stevenson ET, Seals DR. Physiological determinants of $10-\mathrm{km}$ performance in highly trained female runners of different ages. J Appl Physiol (1985). 1995;78(5):1931-41.

[32] Stewart AL, Mills KM, King AC, Haskell WL, Gillis D, Ritter PL. CHAMPS physical activity questionnaire for older adults: Outcomes for interventions. Med Sci Sports Exerc. 2001;33(7):1126-41.

[33] Reuben DB, Magasi S, McCreath HE, Bohannon RW, Wang YC, Bubela DJ, Rymer WZ, Beaumont J, Rine RM, Lai 
J, Gershon RC. Motor assessment using the NIH Toolbox. Neurology. 2013;80(11 Suppl 3):S65-75.

[34] Justice JN, Mani D, Pierpoint LA, Enoka RM. Fatigability of the dorsiflexors and associations among multiple domains of motor function in young and old adults. Exp Gerontol. 2014;55:92-101.

[35] Guralnik JM. Assessing physical performance in the older patient. National Institute on Aging. 2007.

[36] American Thoracic Society. ATS statement: Guidelines for the six-minute walk test. Am J Respir Crit Care Med. 2002;166(1):111-7.

[37] Cho BL, Scarpace D, Alexander NB. Tests of stepping as indicators of mobility, balance, and fall risk in balance-impaired older adults. J Am Geriatr Soc. 2004;52(7):1168-73.

[38] Lunsford BR, Perry J. The standing heel-rise test for ankle plantar flexion: Criterion for normal. Phys Ther. 1995;75(8):694-8.

[39] Vestergaard S, Nayfield SG, Patel KV, Eldadah B, Cesari M, Ferrucci L, Ceresini G, Guralnik JM. Fatigue in a representative population of older persons and its association with functional impairment, functional limitation, and disability. J Gerontol A Biol Sci Med Sci. 2009;64(1):76-82.

[40] Weintraub S, Dikmen SS, Heaton RK, Tulsky DS, Zelazo PD, Bauer PJ, Carlozzi NE, Slotkin J, Blitz D, Wallner-Allen K, Fox NA, Beaumont JL, Mungas D, Nowinski CJ, Richler J, Deocampo JA, Anderson JE, Manly JJ, Borosh B, Havlik R, Conway K, Edwards E, Freund L, King JW, Moy C, Witt E, Gershon RC. Cognition assessment using the NIH Toolbox. Neurology. 2013;80(11 Suppl 3):S54-64.

[41] Tombaugh TN. Trail Making Test A and B: Normative data stratified by age and education. Arch Clin Neuropsychol. 2004;19(2):203-14.

[42] Falconer J, Hughes SL, Naughton BJ, Singer R, Chang RW, Sinacore JM. Self report and performance-based hand function tests as correlates of dependency in the elderly. J Am Geriatr Soc. 1991;39(7):695-9.

[43] Spinelli KJ, Osterberg VR, Meshul CK, Soumyanath A, Unni VK. Curcumin treatment improves motor behavior in $\alpha$ synuclein transgenic mice. PLoS One. 2015;10(6):e0128510.

[44] Khatri DK, Juvekar AR. Neuroprotective effect of curcumin as evinced by abrogation of rotenone-induced motor deficits, oxidative and mitochondrial dysfunctions in mouse model of Parkinson's disease. Pharmacol Biochem Behav. 2016;150151:39-47.

[45] Cox KH, Pipingas A, Scholey AB. Investigation of the effects of solid lipid curcumin on cognition and mood in a healthy older population. J Psychopharmacol. 2015;29(5): 642-51.

[46] Yin HL, Wang YL, Li JF, Han B, Zhang XX, Wang YT, Geng $\mathrm{S}$. Effects of curcumin on hippocampal expression of $\mathrm{NgR}$ and axonal regeneration in $\mathrm{A} \beta$-induced cognitive disorder rats. Genet Mol Res. 2014;13(1):2039-47.

[47] Wang P, Su C, Li R, Wang H, Ren Y, Sun H, Shi J, Tian J, Jiang S. Mechanisms and effects of curcumin on spatial learning and memory improvement in APPswe/PS1dE9 mice. J Neurosci Res. 2014;92(2):218-31.

[48] Isik AT, Celik T, Ulusoy G, Ongoru O, Elibol B, Doruk H, Bozoglu E, Kayir H, Mass MR, Akman S. Curcumin ameliorates impaired insulin/IGF signalling and memory deficit in a streptozotocin-treated rat model. Age (Dordr). 2009;31(1):39-49.
[49] Hoppe JB, Coradini K, Frozza RL, Oliveira CM, Meneghetti AB, Bernardi A, Pires ES, Beck RC, Salbego CG. Free and nanoencapsulated curcumin suppress beta-amyloid-induced cognitive impairments in rats: Involvement of BDNF and Akt/GSK-3 $\beta$ signaling pathway. Neurobiol Learn Mem. 2013;106:134-44.

[50] Nam SM, Choi JH, Yoo DY, Kim W, Jung HY, Kim JW, Yoo M, Lee S, Kim CJ, Yoon YS, Hwang IK. Effects of curcumin (Curcuma longa) on learning and spatial memory as well as cell proliferation and neuroblast differentiation in adult and aged mice by upregulating brain-derived neurotrophic factor and CREB signaling. J Med Food. 2014;17(6): 641-9.

[51] Sun CY, Qi SS, Zhou P, Cui HR, Chen SX, Dai KY, Tang ML. Neurobiological and pharmacological validity of curcumin in ameliorating memory performance of senescence-accelerated mice. Pharmacol Biochem Behav. 2013;105:76-82.

[52] Belviranli M, Okudan N, Atalik KE, Oz M. Curcumin improves spatial memory and decreases oxidative damage in aged female rats. Biogerontology. 2013;14(2):187-96.

[53] Yu SY, Zhang M, Luo J, Zhang L, Shao Y, Li G. Curcumin ameliorates memory deficits via neuronal nitric oxide synthase in aged mice. Prog Neuropsychopharmacol Biol Psychiatry. 2013;45:47-53.

[54] Dong S, Zeng Q, Mitchell ES, Xiu J, Duan Y, Li C, Tiwari JK, Hu Y, Cao X, Zhao Z. Curcumin enhances neurogenesis and cognition in aged rats: Implications for transcriptional interactions related to growth and synaptic plasticity. PLoS One. 2012;7(2):e31211.

[55] Rainey-Smith SR, Brown BM, Sohrabi HR, Shah T, Goozee KG, Gupta VB, Martins RN. Curcumin and cognition: A randomised, placebo-controlled, double-blind study of community-dwelling older adults. $\mathrm{Br} \mathrm{J}$ Nutr. 2016;115(12):2106-13.

[56] Naiberg MR, Newton DF, Goldstein BI. Flow-mediated dilation and neurocognition: Systematic review and future directions. Psychosom Med. 2016;78(2):192-207.

[57] Oberg T, Karsznia A, Oberg K. Basic gait parameters: Reference data for normal subjects, 10-79 years of age. J Rehabil Res Dev. 1993;30(2):210-23.

[58] Troosters T, Gosselink R, Decramer M. Six minute walking distance in healthy elderly subjects. Eur Respir J. 1999;14(2):270-4.

[59] Bohannon RW, Bubela DJ, Magasi SR, Wang YC, Gershon RC. Sit-to-stand test: Performance and determinants across the age-span. Isokinet Exerc Sci. 2010;18(4):235-40.

[60] Bohannon RW, Magasi S. Identification of dynapenia in older adults through the use of grip strength t-scores. Muscle Nerve. 2015;51(1):102-5.

[61] Carlozzi NE, Beaumont JL, Tulsky DS, Gershon RC. The NIH Toolbox Pattern Comparison Processing Speed Test: Normative data. Arch Clin Neuropsychol. 2015;30(5): 359-68.

[62] Mungas D, Heaton R, Tulsky D, Zelazo PD, Slotkin J, Blitz D, Lai JS, Gershon R. Factor structure, convergent validity, and discriminant validity of the NIH Toolbox Cognitive Health Battery (NIHTB-CHB) in adults. J Int Neuropsychol Soc. 2014;20(6):579-87.

[63] Dikmen SS, Bauer PJ, Weintraub S, Mungas D, Slotkin J, Beaumont JL, Gershon R, Temkin NR, Heaton RK. Measuring episodic memory across the lifespan: NIH Toolbox 
Picture Sequence Memory Test. J Int Neuropsychol Soc. 2014;20(6):611-9.

[64] Heaton RK, Akshoomoff N, Tulsky D, Mungas D, Weintraub S, Dikmen S, Beaumont J, Casaletto KB, Conway K, Slotkin J, Gershon R. Reliability and validity of composite scores from the NIH Toolbox Cognition Battery in adults. J Int Neuropsychol Soc. 2014;20(6):588-98.

[65] Zelazo PD, Anderson JE, Richler J, Wallner-Allen K, Beaumont JL, Conway KP, Gershon R, Weintraub S. NIH Toolbox Cognition Battery $(\mathrm{CB})$ : Validation of executive function measures in adults. J Int Neuropsychol Soc. 2014;20(6): 620-9.

[66] Weintraub S, Dikmen SS, Heaton RK, Tulsky DS, Zelazo PD, Slotkin J, Carlozzi NE, Bauer PJ, Wallner-Allen K, Fox N, Havlik R, Beaumont JL, Mungas D, Manly JJ, Moy C, Conway K, Edwards E, Nowinski CJ, Gershon R. The cognition battery of the NIH toolbox for assessment of neurological and behavioral function: Validation in an adult sample. J Int Neuropsychol Soc. 2014;20(6):567-78. 